\title{
Bacterias en superficies contactadas durante las tomas radiográficas intraorales
}

\author{
Bacteria in contacting surfaces during intraoral radiographies procedures \\ Guihan Lee ${ }^{1, a}$, Victor Calderón-Ubaquí ${ }^{1, b}$, Sonia Sacsaquispe-Contreras ${ }^{1, c}$
}

\section{RESUMEN}

Objetivo: Determinar la presencia de bacterias mediante el análisis microbiológico en las superficies contactadas por el operador durante la toma y procesado de radiografías intraorales en diferentes momentos del día en el Servicio de Radiología Oral de la UPCH. Materiales y métodos: Se realizó un muestreo en nueve superficies del servicio de radiología oral. Las muestras se tomaron en dos momentos por el mismo investigador; al inicio y al finalizar las actividades en el servicio, se realizó el hisopado de las superficies con Caldo de Tripticasa Soya (TSB). Las muestras fueron inoculadas e incubadas en tres medios de cultivos (Agar Plate Count, Agar Sangre Cordero y Agar Cetrimide). Luego se realizó el conteo respectivo de Unidad Formadoras de Colonias (UFC) y también se realizó la tinción Gram. Resultados: Se encontró una alta cantidad concentración de bacterias (4180 UFC/mL) y hongos en el servicio radiología oral. Los cocos gram positivos fueron los microorganismos encontrados con más frecuencia y los bacilos gram negativos fueron menos encontradas. Conclusiones: Existe una gran contaminación de bacterias en el servicio de radiología oral. Al finalizar las actividades disminuye la cantidad de bacterias, pero aumenta la variedad de bacterias.

\section{PALABRAS CLAVE: Control de infecciones, Desinfección, Radiografía dental, Microbiología}

\section{SUMMARY}

Objective: Determinate the presence of bacteria through a microbiological analysis of contacting surfaces in a radiology service from the operator during the taking and process of intraoral radiographies in different moments of the day. Materials and methods: A sample was taken from nine surfaces of the oral radiography service. Samples were taken with a cotton stick swap with Triptic Soy Broth (TSB) in two different moments by the same investigator; at beginning and that the end of activities. The samples were inoculated and incubated in three different cultivar measures (Plate Count Agar, Sheep Blood Agar and Cetrimide Agar) and also Gram stein was realized. Results: A high concentration of bacteria $(4180 \mathrm{UFC} / \mathrm{mL})$ and fungus was found in the oral radiology service. The coccus gram-positive was most frequently found microorganism and bacillus gram-negative was poorly found microorganism in this study. Conclusions: A high of contamination with bacteria was found in the oral radiology service. At the end of activities of the day, decrease the quantity of bacteria, but increase variety of bacteria.

\section{KEY WORDS: Infection control, disinfection, radiography, dental, microbiology}

\footnotetext{
Facultad de Estomatología, Universidad Peruana Cayetano Heredia. Lima, Perú.

Cirujano Dentista

Especialista en Radiología

Doctor en Estomatología
} 


\section{INTRODUCCIÓN}

Generalmente los procedimientos de tomas radiográficas no son invasivos, sin embargo siempre existe un riesgo de la contaminación por el procedimiento que se realizan en el interior de la cavidad oral donde existen los microorganismos (1-3). La aplicación de medios y medidas para la bioseguridad es aplicable a todas las acciones que realiza el profesional de salud, sin embargo en la aplicación de las técnicas radiográficas podemos observar frecuentemente que estos principios de bioseguridad no son, ni responsables, ni correctamente aplicados (1-4). Aunque la American Dental Association publicó una guía de bioseguridad en la práctica de radiología oral $(2,3)$; lamentablemente no existe un mecanismo que supervise la aplicación de estos medios y medidas (3, 6-10).

El objetivo de la presente investigación fue determinar el número y tipos de bacterias de acuerdo a la coloración de Gram, existentes en las superficies que son contactadas por el operador durante las tomas radiográficas intraorales en el servicio de Radiología Oral y Maxilofacial de la Clínica Estomatológica Central de la Universidad Peruana Cayetano Heredia en un día del mes del noviembre del año 2010.

\section{MATERIAL Y METODOS}

Se evaluaron en total nueve superficies contactadas por el operador durante la toma de radiografías intraorales en el Servicio Radiología Oral y Maxilofacial de la Clínica Dental (Figuras 1, 2 y 3). Las super- ficies seleccionadas fueron: 5 superficies del cuarto de tomas radiografías intraorales (envoltura de placa radiográfica periapical nueva, perilla de la puerta del cuarto de toma, disparador de rayos $\mathrm{X}$, cabezal de rayos X y superficie externa del mandil plomado) y 4 superficies del cuarto oscuro (superficie de la mesa del trabajo, manija de la puerta giratoria de cuarto oscuro, superficie de la bandeja de entrada de radiografías en la maquina reveladora y interruptor de luz).

Se preparó los siguientes medios de cultivo y caldo antes de empezar las actividades: 54 Agar Plate Count (PC), 18 Agar Sangre de cordero (AS), 18 Agar cetrimide (AC) y 54 tubos con $1 \mathrm{ml}$ de Caldo de Tripticasa Soya $($ Triptic Soy Broth $=$ TSB). Los hisopos fueron envueltos en papel kraft y luego esterilizados al calor seco a una temperatura de $170^{\circ} \mathrm{C}$ por 60 minutos.

Para la toma de muestra se abrió la envoltura del hisopo, se destapó el tubo que contenía el caldo, se introdujo el hisopo en el tubo con el caldo y luego se friccionó las superficies contactadas por el operador durante la toma y procesado de radiografías intraorales en los ambientes del servicio de radiología oral, luego se introdujo el hisopo en el mismo tubo de ensayo y seguidamente se cerró con una tapa de goma o de algodón.

Este procedimiento se realizó en los siguientes momentos: el primer hisopado de superficies se realizó al inicio (08:00 horas) antes de empezar las actividades del servicio y la segunda toma de muestras se realizó al finalizar (18.00 horas) las actividades del servicio, después de la última toma radiográfica

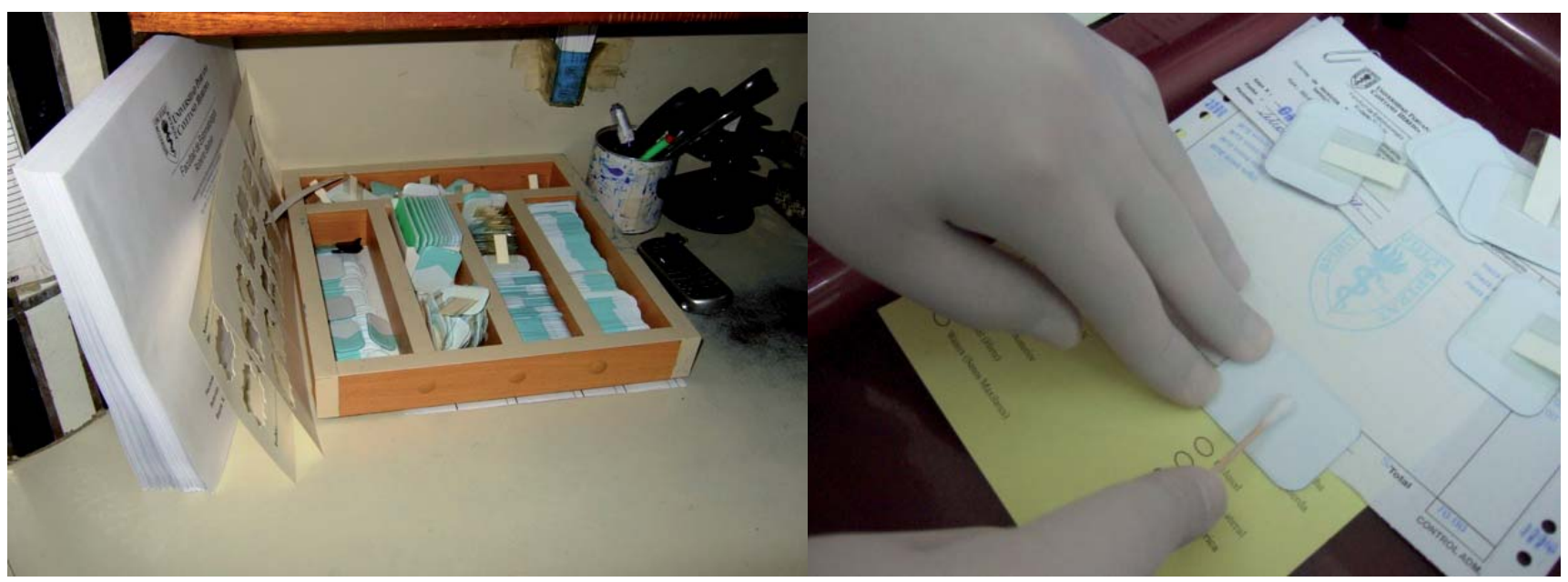

Figura 1. Surtidor de placa radiográfica y toma de muestra 


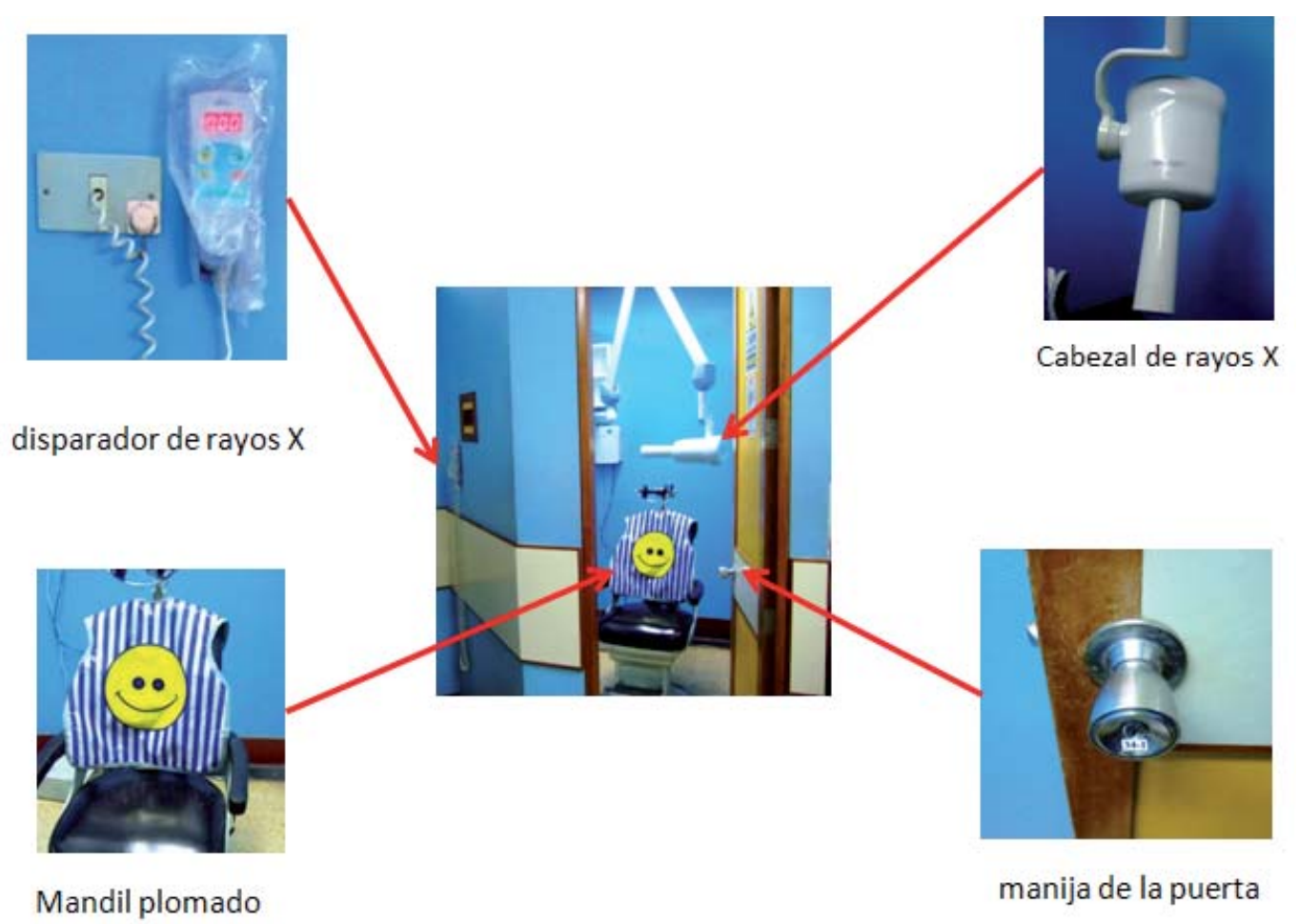

Figura 2. Superficies de contacto seleccionada en el cuarto de toma de radiografías intra-orales: disparador de rayos $\mathrm{X}$, cabezal de rayos $\mathrm{X}$, superficie exterior de mandil plomado y perilla de la puerta

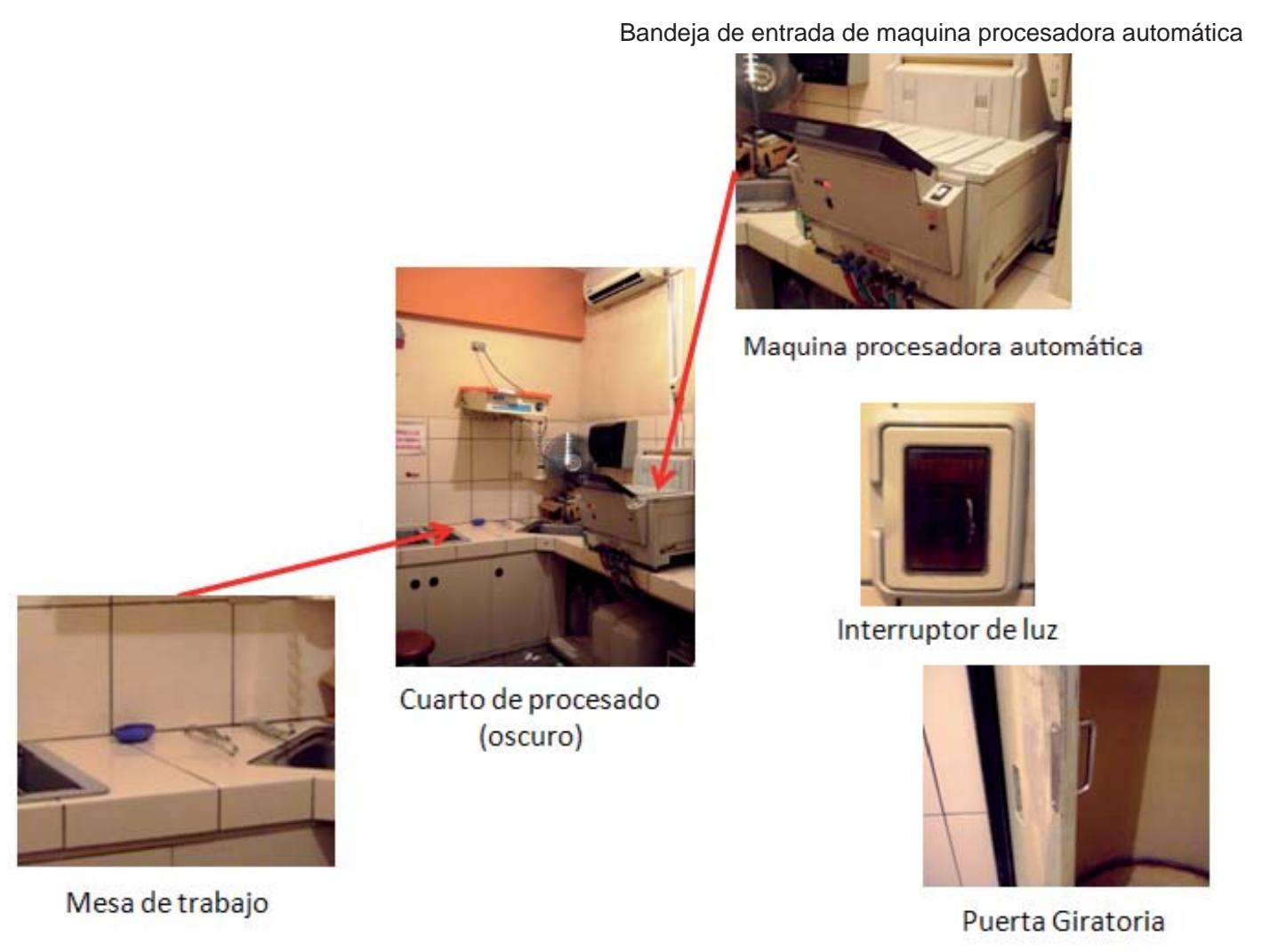

Figura 3. Figura 3. Superficies de contacto en el cuarto oscuro: mesa de trabajo, bandeja de entrada de maquina procesadora automática, interruptor de luz y manija de puerta giratoria 
en el mismo cuarto de toma seleccionado para el estudio y en las mismas superficies. Las muestras tomadas se llevaron al laboratorio de microbiología de la Facultad de Ciencia de la UPCH y se inocularon las muestras empleando los siguientes métodos: el método de placa vertida (The Pour Plate) en agar plate count: Se realizaron de manera inmediata. Se realizó las diluciones de $10^{-1}$ y $10^{-2}$, y el método de estriado (Streak-Plate Technique) en agar sangre y agar cetrimide. Se incubaron todos los medios de cultivo a $37^{\circ} \mathrm{C}$ de temperatura durante 24 horas. Solo el medio de Agar sangre fue incubado en condiciones microaerofilia.

Tabla 1. Microorganismos (UFC/ml) encontrados en superficies contactadas en tomas radiográficas intraorales al inicio y al final de las actividades.

\begin{tabular}{llcc}
\hline \multicolumn{1}{c}{ Área } & \multicolumn{1}{c}{ Superficies } & Inicio UFC/ml & Final UFC/ml \\
\hline \multirow{3}{*}{$\begin{array}{l}\text { Cuarto de toma } \\
\text { de radiografías }\end{array}$} & Envoltura de Placa radiográfica & 0 & 10 \\
intraorales & Interruptor o disparador & 410 & 250 \\
& Tubo o Cabezal de rayos X & 2920 & 340 \\
Sub-total & Mandil plomado & 730 & 370 \\
Cuarto oscuro & Mesa de trabajo & 120 & 130 \\
& Manija de puerta giratoria & 4180 & 1100 \\
& Bandeja de entrada maquina reve- & 80 & 380 \\
& ladora & 50 & 80 \\
Sub-total & Interruptor de luz & 30 & 220 \\
Total & & 350 & 40 \\
\hline
\end{tabular}

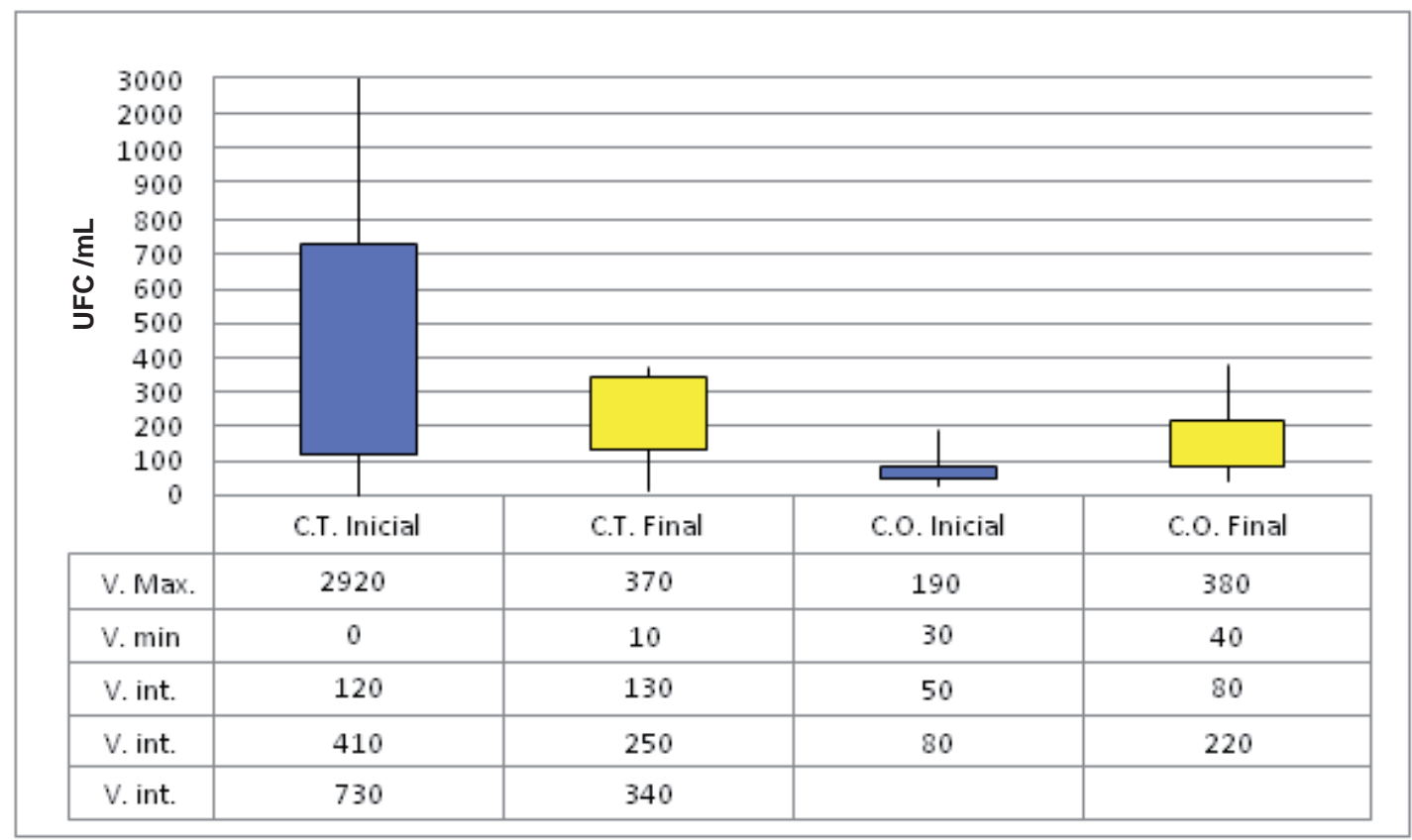

Grafico 1. Cantidad de microorganismos (UFC/mL) encontrados en superficies contactadas en el cuarto de tomas radiográficas y cuarto oscuro, al inicio y al final de las actividades. C.T. Inicial: Cuarto de Toma al inicio de las actividades, C.T. Final: Cuarto de Toma al final de las actividades, C.O. Inicial: Cuarto Oscuro al inicio de las actividades, C.O. Final: Cuarto Oscuro al final de las actividades. 
Transcurrido el tiempo se realizaron las observaciones macroscópicas para el conteo respectivo para saber la cantidad de microorganismos obtenidos durante hisopado de la superficie. Luego se seleccionó colonias con diferentes morfologías, se retiró con asa de siembra y se realizó coloraciones de Gram para determinar las morfologías y tipos bacterianas (cocos y bacilos).

\section{RESULTADOS}

En Agar PC (Plate Count) encontró una gran cantidad de UFC con el color blanco-amarillo al inicio de las actividades, el número de colonias varió entre 0 a 2920 UFC/mL y las áreas de mayor contaminación en el cuarto de toma de radiografía intraoral obtuvo un sub-total de $4180 \mathrm{UFC} / \mathrm{mL}$ y el área de menor contaminación en el cuarto de procesamiento obtuvo un sub-total de $350 \mathrm{UFC} / \mathrm{mL}$. Al finalizar las actividades encontró menos cantidades de UFC, que varió entre de 10 a $390 \mathrm{UFC} / \mathrm{mL}$, de igual forma la mayor concentración se encontró en el cuarto de toma de radio- grafía intraoral con un sub-total de $1100 \mathrm{UFC} / \mathrm{mL}$ y en cuarto oscuro se halló un sub-total de $720 \mathrm{UFC} / \mathrm{mL}$ (Tabla 1, gráficos 1 y 2).

Luego, al observar al microscopio, en las muestras tomadas al inicio de las actividades se encontró cocos gram positivos, cocos gram negativos, bacilos gram positivos y hongos y al finalizar las actividades se encontró adicionalmente otros microorganismos como bacilos gram negativos (Tablas 2 y 3 ).

En el agar sangre, al inicio de las actividades, microscópicamente se encontró Cocos Gram Positivos con $\alpha$ y $\gamma$ hemólisis, Cocos Gram Negativos con $\gamma$ hemólisis, Bacilos Gram Positivos con $\alpha$ y $\gamma$ hemólisis, Bacilos Gram Negativos con $\alpha$ hemólisis. Al finalizar las actividades se encontró mismo tipos de bacterias que al inicio, adicionalmente Cocos Gram Positivos con $\alpha, \beta$ y $\gamma$ hemólisis, Cocos Gram Negativos con $\gamma$ hemólisis, Bacilos Gram Positivos con $\gamma$ hemólisis, Bacilos Gram Negativos con $\gamma$ hemólisis y hongos (Tabla 4).

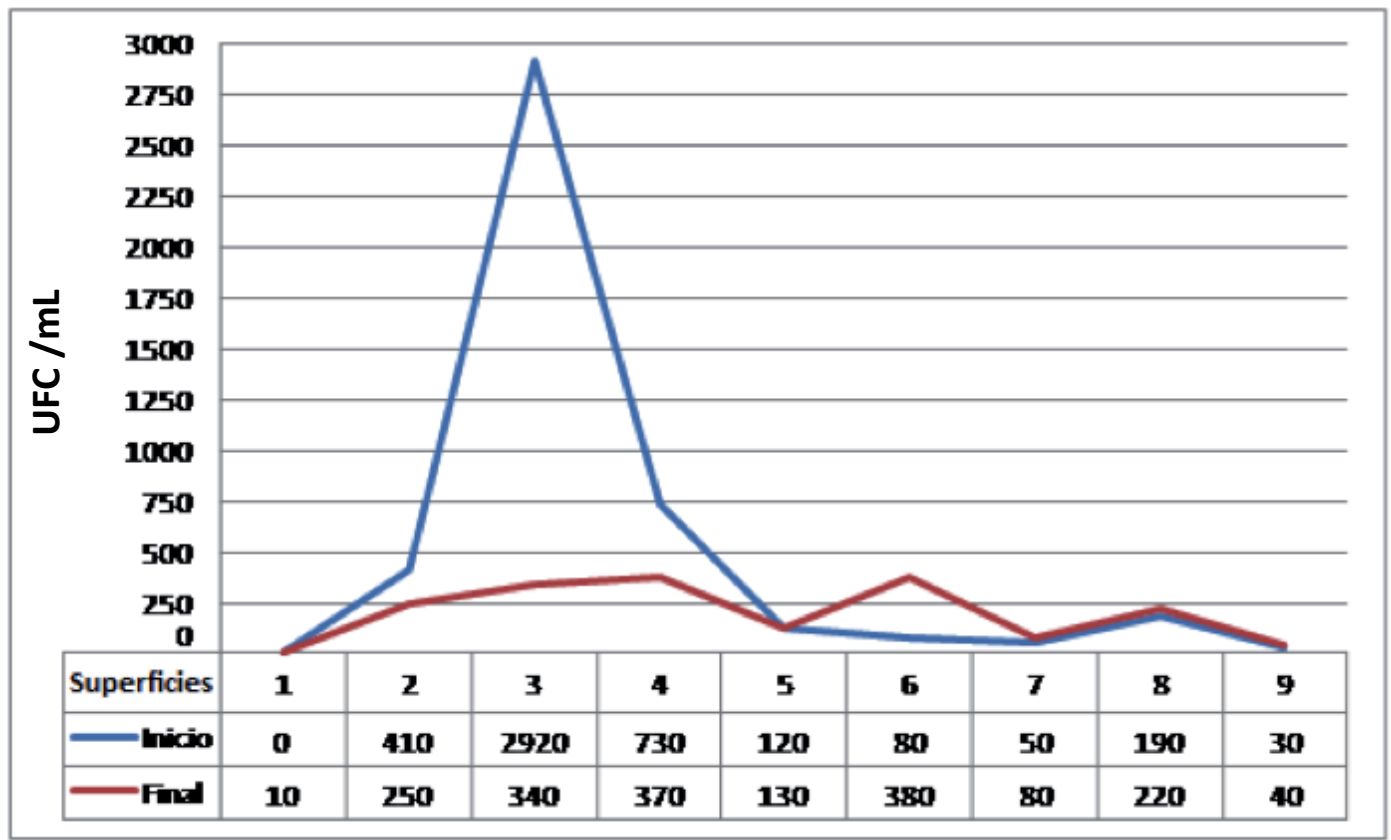

Gráfico 2. Cantidad de microorganismos (UFC/mL) por superficies contactadas en tomas radiográficas intraorales al inicio y al final de las actividades.

1. Envoltura de placas radiográficas periapicales antes de tomar la radiografía, 2. Perilla de la puerta del cuarto de toma de radiografías intraorales, 3. Disparador de cuarto de toma de radiografías intraorales, 4. Cabezal de rayos $\mathrm{X}$ de cuarto de toma de radiografías intraorales, 5. Superficie externa del mandil plomado, 6. Superficie de la mesa del trabajo de cuarto oscuro, 7. Manija de la puerta giratoria de cuarto oscuro, 8. Superficie de la bandeja de entrada de radiografías en la maquina reveladora de cuarto oscuro, 9. Interruptor de luz de cuarto oscuro. 
Tabla 2. Microorganismos según morfología en coloración Gram encontrados en superficies contactadas en tomas radiográficas intraorales al inicio y al final de las actividades.

\begin{tabular}{|c|c|c|c|c|c|}
\hline \multirow{2}{*}{ Área } & \multirow{2}{*}{ Superficies } & \multicolumn{2}{|l|}{ Inicio } & \multicolumn{2}{|l|}{ Final } \\
\hline & & Morfología & Gram & Morfología & Gram \\
\hline \multirow{13}{*}{$\begin{array}{l}\text { Cuarto de toma } \\
\text { de radiografías } \\
\text { intraorales: }\end{array}$} & $\begin{array}{l}\text { Envoltura placas radio- } \\
\text { gráficas }\end{array}$ & -------------- & ------- & Cocos en Cadenas & + \\
\hline & & Cocos en cadenas & + & $\begin{array}{l}\text { Cocos en cadenas cortas/ } \\
\text { racimos de uvas }\end{array}$ & + \\
\hline & Perilla de la puerta & Diplo/Tetra Cocos & + & Cocos en cadenas & + \\
\hline & & --- & & Hongos & ------- \\
\hline & & Cocos en cadenas cortas & + & $\begin{array}{l}\text { Bacilos Curvos Pleomor- } \\
\text { fico }\end{array}$ & + \\
\hline & Disparador de rayos $\mathrm{X}$ & Diplococos & + & Bacilos Curvos & - \\
\hline & & Otro & ------- & ------------- & \\
\hline & & Tetra cocos & + & Cocos agrupados & + \\
\hline & Cabezal de rayos $\mathrm{X}$ & Cocos en cadenas & - & Bacilos Curvos & - \\
\hline & & ------------- & ------- & Bacilos Rectos & - \\
\hline & & Diplococos & - & Cocos agrupados & + \\
\hline & Superficie exterior & Cocos en cadenas cortas & + & Diplococos & - \\
\hline & Mandil plomado & Bacilo recto & + & Bacilos rectos & - \\
\hline \multirow{9}{*}{ Cuarto oscuro: } & \multirow{2}{*}{ Mesa de trabajo } & Diplococos & + & Cocos agrupados & + \\
\hline & & Tetra cocos & + & ------------- & \\
\hline & \multirow{2}{*}{ Manija de puerta giratoria } & Cocos en cadenas & + & Cocos Agrupados & + \\
\hline & & Hongo & ------- & Bacilos Curvos & + \\
\hline & \multirow{3}{*}{$\begin{array}{l}\text { Bandeja de entrada ma- } \\
\text { quina reveladora }\end{array}$} & Tetra cocos & + & Diplococos & + \\
\hline & & Hongos & ------- & Cocos en cadenas & + \\
\hline & & ------------- & - & Hongos & ----- \\
\hline & \multirow{2}{*}{ Interruptor de luz } & Diplococos & + & Cocos Agrupados & + \\
\hline & & Hongos & ------- & Diplococos en cadenas & - \\
\hline
\end{tabular}

En el agar cetrimide no se observó algún crecimiento bacteriano macroscópicamente.

\section{DISCUSIÓN}

Existe pocos estudios publicados de control de infecciones realizados en el servicio de radiología oral y los que existen no detallan las medidas de control de infecciones de los servicios, ni los medios utilizados $(3,11,12)$. Al revisar estudios donde analizan la efectividad de la instauración de protocolos de control de infección en el servicio de radiología oral podemos observar el déficit ó falla en los procedimientos de limpieza en el servicio, ya que los resultados demues- tran una disminución en la cantidad de bacterias encontradas al final casi a la mitad de lo encontrado al inicio (3) (Gráfico 1); sin embargo los conteos siguen siendo significativos, existiendo un alto grado de contaminación (3).

En el presente estudio, obtuvo un valor de $6350 \mathrm{UFC} /$ ml en 2 momentos como la concentración acumulada total del estudio. Las concentraciones de bacterias al inicio de las actividades del servicio de radiología oral, obteniéndose $4530 \mathrm{UFC} / \mathrm{mL}$ y al finalizar las actividades con concentraciones de 1820 UFC/ml (Tabla 1 y gráficos 1 y 2), esta disminución podría deberse a 2 posibilidades: a) las bacterias presentes en las su- 
Tabla 3. Tipos de microorganismos por superficies contactadas en tomas radiográficas intraorales al inicio y al final de las actividades.

\begin{tabular}{|c|c|c|c|c|c|c|c|c|c|c|}
\hline \multirow{2}{*}{$\begin{array}{l}\text { Superficies } \\
\text { de contacto }\end{array}$} & \multicolumn{2}{|c|}{ Cocos Gram + } & \multicolumn{2}{|c|}{ Cocos gram - } & \multicolumn{2}{|c|}{ Bacilos gram +} & \multicolumn{2}{|c|}{ Bacilos gram - } & \multicolumn{2}{|c|}{ Otros } \\
\hline & I & $\mathbf{F}$ & $\mathbf{I}$ & $\mathbf{F}$ & $\mathbf{I}$ & $\mathbf{F}$ & I & $\mathbf{F}$ & I & $\mathbf{F}$ \\
\hline 1 & $(-)$ & $\mathrm{X}$ & $(-)$ & $\mathrm{X}$ & $(-)$ & $(-)$ & $(-)$ & $(-)$ & $(-)$ & $(-)$ \\
\hline 2 & $\mathrm{X}$ & $\mathrm{X}$ & $(-)$ & $(-)$ & $(-)$ & $\mathrm{X}$ & $(-)$ & $(-)$ & $(-)$ & $\mathrm{X}$ \\
\hline 3 & $\mathrm{X}$ & $\mathrm{X}$ & $(-)$ & $(-)$ & $(-)$ & $(-)$ & $(-)$ & $\mathrm{X}$ & $\mathrm{X}$ & $(-)$ \\
\hline 4 & $\mathrm{X}$ & $\mathrm{X}$ & $\mathrm{X}$ & $(-)$ & $(-)$ & $(-)$ & $(-)$ & $\mathrm{X}$ & $(-)$ & $(-)$ \\
\hline 5 & $\mathrm{X}$ & $\mathrm{X}$ & $\mathrm{X}$ & $\mathrm{X}$ & $\mathrm{X}$ & $(-)$ & $(-)$ & $\mathrm{X}$ & $(-)$ & $(-)$ \\
\hline 6 & $\mathrm{X}$ & $\mathrm{X}$ & $(-)$ & $(-)$ & $(-)$ & $(-)$ & $(-)$ & $(-)$ & $(-)$ & $(-)$ \\
\hline 7 & $\mathrm{X}$ & $\mathrm{X}$ & $(-)$ & $(-)$ & $(-)$ & $\mathrm{X}$ & $(-)$ & $(-)$ & $\mathrm{X}$ & $(-)$ \\
\hline 8 & $\mathrm{X}$ & $\mathrm{X}$ & $(-)$ & $(-)$ & $(-)$ & $(-)$ & $(-)$ & $(-)$ & $\mathrm{X}$ & $\mathrm{X}$ \\
\hline 9 & $\mathrm{X}$ & $\mathrm{X}$ & $(-)$ & $\mathrm{X}$ & $(-)$ & $(-)$ & $(-)$ & $(-)$ & $\mathrm{X}$ & $(-)$ \\
\hline
\end{tabular}

I: Al inicio de las actividades $\mathbf{F}$ : Al final de las actividades.

1. Envoltura de placas radiográficas periapicales antes de tomar la radiografía,

2. Perilla de la puerta del cuarto de toma de radiografías intraorales, 3. Disparador de cuarto de toma de radiografías intraorales, 4 . Cabezal de rayos $\mathrm{X}$ de cuarto de toma de radiografías intraorales, 5. Superficie externa del mandil plomado, 6. Superficie de la mesa del trabajo de cuarto oscuro, 7. Manija de la puerta giratoria de cuarto oscuro, 8. Superficie de la bandeja de entrada de radiografías en la maquina reveladora de cuarto oscuro, 9. Interruptor de luz de cuarto oscuro,

Tabla 4. Microorganismos encontrados en el cultivo de muestras de superficies contactadas en tomas radiográficas intraorales al inicio y al final de las actividades.

\begin{tabular}{|c|c|c|c|c|c|}
\hline & \multirow{2}{*}{$\begin{array}{l}\text { Superficies } \\
\text { Morfología }\end{array}$} & \multicolumn{2}{|l|}{ Inicio } & \multicolumn{2}{|c|}{ Final } \\
\hline & & Gram (hemólisis) & Morfología & Gram (hemólisis) & \\
\hline \multirow{11}{*}{$\begin{array}{l}\text { Cuarto de toma de } \\
\text { radiografías intrao- } \\
\text { rales: }\end{array}$} & Envoltura placa radiográfica & Diplococcus & $+(\gamma)$ & Cocos en cadenas & $-(\gamma)$ \\
\hline & Perilla de la puerta & Bacilos grandes & $-(\alpha)$ & & \\
\hline & & Cocos pleomorfo & $+(\gamma)$ & & \\
\hline & Disparador de rayos $\mathrm{X}$ & Diplococos & $+(\alpha)$ & & (1) \\
\hline & & Diplococos & $-(\gamma)$ & Dipiococos & $+(\gamma)$ \\
\hline & Cabezal de rayos $\mathrm{X}$ & Diplococos & $+(\gamma)$ & & \\
\hline & & Bacilos grandes & $+(\gamma)$ & Diplo/Tetra cocos & $+(\gamma)$ \\
\hline & & Bacilos grandes & $+(\alpha)$ & & \\
\hline & Superficie exterior de Mandil & Bacilos pleomorfo & $+(\gamma)$ & & \\
\hline & plomado & Bacilos grandes pleomorfo & $+(\alpha)$ & ---------- & $----\cdot$ \\
\hline & & Diplo/tetracocos & $+(\gamma)$ & & \\
\hline \multirow[t]{7}{*}{ Cuarto oscuro: } & Mesa de trabajo & & & Diplococos & $+(\beta)$ \\
\hline & & & & Bacilos en pareja & $+(\gamma)$ \\
\hline & Manija de puerta giratoria & & & Bacilos Curvos & $-(\gamma)$ \\
\hline & & & & Diplo/Tetra cocos & $+(\gamma)$ \\
\hline & $\begin{array}{c}\text { Bandeja de entrada de maquina } \\
\text { procesadora }\end{array}$ & ------ & $\cdots$ & Cocos en cadenas & $-(\gamma)$ \\
\hline & Interruptor de luz & & & Diplococos & $+(\alpha)$ \\
\hline & & & & Hongos & \\
\hline
\end{tabular}


perficies fueron removidos durante los procedimientos de toma radiografías, ya sea llevados a la boca de paciente. b) debido a la hora de la primera recolección de muestra fue 9:00 am y a la asistente dental, personal técnico u otros del servicio, quienes estaban presentes y observaban la toma de muestra y es muy probable que realizaron mejor limpieza del servicio. Esto nos da una explicación porque disminuyó solo en las 3 superficies (perilla o chapa de la puerta, cabezal de rayos $\mathrm{X}$ y disparador de rayos $\mathrm{X}$ ), mientras el resto de superficies del estudio aumentaron la cantidad de bacterias al finalizar las actividades. Además demuestra que la manera de desinfección del nuestro medio sí funciona, pero aun es deficiente comparando con otros estudios. En tantos otros estudios como en el presente, los ambientes de los servicios de radiología oral presentan un alto grado de contaminación $(3,11,12)$. Silva y col., evaluaron 7 superficies durante 10 días no consecutivos y al azar, en la clínica de radiología oral de la Universidad del Estado de Sao Paulo obteniendo un conteo acumulado de 7546 UFC/placa en las muestras de 48 horas, en donde el valor más alto fue en el tercer día (1767 UFC/placa), y el valor más bajo fue en el octavo día (242 UFC/placa). Sólo en el cuarto de tomas de radiografías obtuvo un acumulado de 2706 UFC/placa (11).

En general, al realizar el análisis de concentraciones de bacterias en el cuarto de toma de radiografía y del cuarto oscuro podemos encontrar que en el cuarto de toma de radiografía intraoral obtuvo mayores concentraciones de microorganismos, especialmente al inicio de las actividades con $4180 \mathrm{UFC} / \mathrm{mL}$ y en cuarto oscuro al inicio de las actividades obtuvo menor concentración de microorganismos con un valor de 350 $\mathrm{UFC} / \mathrm{mL}$. Las bacterias presentes en las superficies fueron trasladas al cuarto oscuro juntos con el guante, esto explicaría porque aumentó la cantidad de bacterias en cuarto oscuro al finalizar las actividades.

Silva y col. demostraron la efectividad de la solución de alcohol clorhexidina $\left(70^{\circ}\right.$ de alcohol con $5 \%$ de clorhexidina) como desinfectante superficial aplicado en las superficie de contacto (placa radiografía, el cabezal del tubo, el sillón dental, mandil plomado, los botones, la barrera protectora ó mandil plomado y mesa de trabajo del cuarto oscuro) en el servicio radiología oral disminuyendo los conteos de microorganismos de 7545 a 1234 UFC/placa (11). Las concentraciones acumuladas obtenidas en las superficies del cuarto oscuro al inicio de las actividades fueron de $350 \mathrm{UFC} / \mathrm{mL}$ (Tabla 1), según el estudio de Silva y col. las muestras obtenidas en la mesa de trabajo del cuarto oscuro dieron un conteo acumulado de 710 UFC/placa (11).

Al determinar e identificar los tipos de bacterias en este estudio, obtenidas de las muestras de las superficies de la Cuarto de toma radiográfica y cuarto oscuro los microorganismos encontrados fueron: Cocos gram positivos, Cocos gram negativos, Bacilos gram positivos, Bacilos gram negativos, Hongo y otros; las bacterias que se encontraron con mayor frecuencia en las superficies fueron los Cocos gram positivos con aspectos de racimos de uvas con diferentes tipos de propiedades hemolíticas y los menos frecuentes fueron los Bacilos gram negativos, sin embargo las cifras al inicio de las actividades se presentaron ligeramente mayores que al final de las actividades del servicio (Gráficos 1 y 2, tablas 2, 3 y 4). Arredondo y col., analizaron 4 superficies (disparador digital, tubo de rayos $\mathrm{x}$, el sillón y maquina de revelado) de la Universidad de Chile se observó que las bacterias más frecuentemente encontradas fueron bacilos gram negativos y cocos gram positivos fueron menos encontrados (12). Según investigaciones recientes donde se han aplicado medios y medidas de control de infecciones demuestran que la presencia de bacterias disminuyó en gran cantidad ó los conteos fueron casi nulos después de haber realizado la desinfección de las áreas de toma de radiografías y cuarto oscuro del servicio de radiología oral $(8,11,12)$.

En el agar cetrimide no se encontró ningún crecimiento de bacterias, ya que dicho agar es exclusivamente para crecimiento Pseudomonas spp (3). Se eligió dicho procedimiento en agar cetrimide por los antecedentes de otros estudios y publicaciones. Y por lo tanto los resultados no significan que se descarta la presencia de dicha especies, sino que simplemente no se observó el crecimiento en estas pruebas sugiriéndose realizar en otro medio de agar para obtener mejores resultados.

El presente estudio demuestra valores altos en los recuentos de Unidades Formadores de Colonias y una gran variedad de tipos de microorganismos en las diferentes superficies del servicio radiología oral, mostrando así un alto riesgo de infección y contaminación comparadas con estudios realizados en Brasil 
y Chile $(3,11,12)$. Esto sugiere que se debe realizar un proyecto que permita identificar cada especie de microorganismos y así poder implementar y desarrollar el empleo de medios y medidas adecuados para la desinfección de cada una de las superficies de contacto al realizar la toma y procesado de las radiografías en el servicio.

\section{CONCLUSIONES}

En el área del cuarto de toma radiografía intraoral al empezar las actividades hubo mayor concentración de bacterias $(4180 \mathrm{UFC} / \mathrm{mL})$ que al finalizar las actividades (1100 UFC/mL). Tanto al inicio como al finalizar hubo mayor contaminación por cocos gram positivos, especialmente en el disparador de rayos X. Al finalizar las actividades se encontró un aumento de los tipos de bacterias que al iniciar las actividades. Existió una disminución significativa en los valores de las concentraciones de bacterias al comparar las muestras al inicio y final (4530 UFC/mL y $1620 \mathrm{UFC} /$ $\mathrm{mL}$ ) de las actividades del servicio Además se encontró un aumento en la variedad de tipos de bacterias en las muestras al inicio y final de las actividades.

Agradecimiento a la MSc. Dora Maurtua Torres, por su colaboración y apoyo en el laboratorio de microbiología, Departamento de Microbiología Facultad de Ciencias y Filosofia - UPCH.

\section{Correspondencia:}

Guihan Lee

Correo electrónico: guihan.lee@upch.pe

\section{REFERENCIAS BIBLIOGRAFICAS}

1. Parks ET, Farman AG. Infection control for dental radiographic procedures in US dental Hygiene programs. Dentomaxillofac Radiol 1992; 21(1): 16-20.

2. American Dental Association. Recommendations in radiographic practices: an update, 1988. JADA. 1989; 118: $115-7$.

3. Lee G. Determinación de la presencia de bacterias por medio de análisis microbiológico durante la práctica radiológica intraoral en el servicio de Radiología Oral y Maxilofacial de la Clínica Estomatológica Central de la Universidad Peruana Cayetano Heredia [Tesis]. Lima, Perú: Universidad Peruana Cayetano Heredia; 2010. URL (Fecha de acceso 09 de mayo del 2016). Disponible en: http://www.cop.org.pe/bib/tesis/ GUIHANLEE.pdf
4. Gay C, Beini L. Tratado de cirugía bucal. Primera edición. Madrid, España: Editorial Ergon; 2004. p. 60 - 5.

5. White SC, Pharoah MJ. Oral radiology principles and interpretation. 5 ed. Madrid: Editorial Mosby; 2000. p. 253-8.

6. Padilla A, Jaynes R. Control de infecciones en radiología oral. 2009. URL (Fecha de acceso 23 Julio 2010). Disponible en: http://www.slideboom.com/ presentations/103485/control-de-infeccion

7. Eltem R, Çankaya H, Ates M, et al. Possible microbial contamination during the development of Intra-oral films. Turk J Med. 2000; 30: 601-4.

8. Elaine B, Vania F, Marcos T. Avaliação da desinfecção de filmes radiográficos periapicais utilizando diferentes soluções; Revista odonto ciencia- Fac. Odonto/ RUCRS. 2006; 52 (21):153-7.

9. Bartoloni JA, Charlton D.G., Flint D.J. Infection control practices in dental radiology. General dentistry. 2003; 51(3):264-72.

10. Palenik C. Infection control practices for dental radiography. Dent Today. 2004; 23(6): 52-5.

11. Silva M, Martins M, Medici E, Castilho J, Olavo A. Evaluation of the efficiency of an infection control protocol in dental radiology by means of microbiological analysis. Cienc Odontol Bras. 2004; 7 (3): 1521.

12. Arredondo D. Aplicación de métodos de asepsia y desinfección en la práctica de la radiología intraoral. [Tesis]. Santiago, Chile: Universidad de Chile. 2006. $56 \mathrm{pp}$.

Recibido : 11/05/2015

Aceptado: 12/12/2015 